\title{
PHARMACOTECHNICAL DEVELOPMENT AND OPTIMIZATION OF MULTILAYERED TABLETS: AN UPDATED INDUSTRIAL REVIEW WITH EMPHASIS ON BILAYER TABLETS
}

\author{
AHMED M. AGIBA ${ }^{1,2 *}$, SOHA SAYED ABUL-ELLA ${ }^{3}$, REHAB A. ABD EL-MONEM ${ }^{4}$
}

${ }^{1}$ Formulation Department, Research and Development Directorate, IDI Pharmaceutical, East of Al Tafreah, Port Said Governorate, Egypt, ${ }^{2}$ Pharmaceutics Department, Faculty of Pharmacy, Sinai University Kantara Campus, Ismailia, Egypt, ${ }^{3}$ Pharmaceutics Department, College of Pharmaceutical Sciences and Ind ustrial Pharmacy, Misr University for Science and Technol ogy, $6^{\text {th }}$ of October City, Egypt, ${ }^{4}$ Industrial Pharmacy Department, College of Pharmaceutical Sciences and Industrial Pharmacy, Misr University for Science and Technology, $6^{\text {th }}$ of October City, Egypt

Email: ahmed.agiba@gmail.com

Received: 20 Mar 2021, Revised and Accepted: 19 May 2021

\begin{abstract}
Fixed-dose combination formulations are multilayered platforms designed for solving complex medication regimens and overcoming poly pharmacy problems especially in chronic diseases with geriatric patients. Multilayered tablets are considered promising avenues to combine different active pharmaceutical ingredients (APIs) for a synergic therapeutic effect, or different formulations of the same API in order to achieve a specific drug release profile. Besides, multilayered tablets can extensively help in avoiding possible interactions between different drugs, as well as optimizing each formulation individually in terms of pharmacokinetics and manufacturability. This review article discusses the most suitable materials used in the manufacturing of multilayered tablets, describes novel approaches to manufacturing improvement and process parameters, the influence of process parameters on layer adhesion, and the characterization tests of multilayered tablets.
\end{abstract}

Keywords: Fixed-dose combination formulations, Multilayered tablets, Novel approaches, Manufacturing improvement, Process parameters, Characterization tests

(C) 2021 The Authors. Published by Innovare Academic Sciences Pvt Ltd. This is an open access article under the CC BY license (https://creativecommons.org/licenses/by/4.0/) DOI: https://dx.doi.org/10.22159/ijap.2021v13i4.41528. Journal homepage: https://innovareacademics.in/journals/index.php/ijap

\section{INTRODUCTION}

Over the last few decades, U. S. Food and Drug Administration (FDA) and European Medicine Agency (EMA) approved a record number of multilayered tablets as a combinatory multidrug therapeutic system, hence multilayered tablets possess some advantages over other solid dosage forms. For instance, two or more incompatible active pharmaceutical ingredients (APIs) can be incorporated together into a single tablet dosage form in two or more layers for preventing possible API interactions. In certain cases, a buffer layer is inserted in between of API-containing layers to overcome the chemical instability associated with APIs [1, 2]. Besides, in multilayered tablets, drugs with different drug release profiles, such as immediate and extended-release can be compressed together to reduce dosing frequency from being multiple-dosing to once-daily dosing, thereby improving patient compliance [3-5].

Multilayered tablets are available in a range of bilayer to quadrable layered tablets. Generally, multilayered tablets are classified according to the layering system [6] into bilayer tablets, triplelayered tablets, tablet in tablet, and surrounded coated core tablets, while classified according to drug release kinetics [6] into zero-order sustained release profile, quick/slow delivery system, timeprogrammed release profile, and bimodal release profile. By changing the formulation composition, individual layer design, and dosage form geometry, tablets with different drug release profiles can be achieved. For example, in zero-order sustained-release formulations [7], tablets usually comprise hydrophilic/hydrophobic polymeric matrix system or barrier layers in which the drug release pattern is controlled by either coating the hydrophilic matrix core tablet on both sides with hydrophobic polymers to achieve sustainedrelease, or by coating only one side with hydrophobic polymers and the other side with hydrophilic polymers or leaving uncovered to allow controlled-release of the drug substance in different release medias; in case of quick/slow drug delivery systems [8], tablets exhibit an initial rapid drug release, followed by a second phase of prolonged drug release to maintain a constant plasma concentration; while in case of time-programmed delivery systems [9], tablets usually consist of a tablet core coated with different types of hydrophilic and/or hydrophobic polymers in order to initially achieve an immediate drug release, followed by a time-controlled/pulsatile drug release over a period of time. Lastly, in bimodal release systems [10], tablets show an initial rapid drug release, followed by slow release of the drug substance, then a third phase of rapid drug release, i.e., tablets exhibit sigmoidal release profiles.

\section{Common challenges in manufacturing of multilayered tablets}

Multilayered tablets are mostly composed of a tablet core and barrier layers, or a tablet core and an outer tablet or shell as in cases of tablet in tablet and press-coated tablets; therefore, the manufacturing of multilayered tablets is a big challenge and requires careful selection of excipients, and optimization of process parameters and formulation conditions. The most recurring challenges in the manufacturing of multilayered tablets are related to the individual layer and total tablet weight [11], insufficient mechanical strength [12], inaccurate regulation of multilayers [13], elastic modulus mismatching between the adjacent layers [14], tablet's propensity for intralayer capping and interlayer delamination, i.e., separation of adjacent layers along with the interface either during tablet manufacturing or during storage process $[15,16]$, long-term chemical and physical integrity during shelf-life [17], and impact of high temperature and humidity on interlayer adhesion during storage [18].

Understanding of these challenges is crucial and requires paying close attention to physicochemical and solid-state properties of both API and excipients, optimization of formulation and tableting process, and identifying the criticality of the process (critical process parameters and quality attributes). The key process parameters for manufacturing of multilayered tablets with ideal properties are concerned with the determination of the proper mechanical properties of each individual layer, optimization of the first layer compression force, maximization of interlayer adhesion between the adjacent layers, determination of optimal layer sequence and weight ratio, and selection of the appropriate multilayered tablet press equipped with the consistent weight-controlled delivery system.

Common industrial problems associated with manufacturing multilayered tablets

Understanding tablet defects is crucial for successfully tablet manufacturing. Hence, these defects usually appear as visual cracks on the external surface of the tablet dosage, leading to potential 
product failures in the efficacy and stability of the dosage form, particularly in cases of modified-release multilayer tablets or presscoated designs [19]. These defects extend from horizontal detachment of the tablet upper part, which is commonly known as capping [20], to cracks formation within the tablet body, which is called delamination [21, 22], as shown in (fig. 1) [23]. Multilayered tablets are liable to delamination since they are susceptible to separate into two individual layers, owing to their remarkable changes in the Young's modulus of elasticity. Hence, the elastic recovery resulted from the compaction process has a negative effect on the tablet bonds by causing internal stresses and promoting the bonding rupture, which in turn leads to a strong decrease in the tablet mechanical strength $[24,25]$. This phenomenon usually appears clearly when the air entrapped in the die during the compaction process. Moreover, large residual air pockets can firmly store a sufficient amount of elastic energy to promote cracks formation during decompression [26]. Capping is another common tablet manufacturing defect, which is primarily related to the press speed, hence the increase in press speed leads to a remarkable increase in elastic energy [27]. Moreover, the punch shape plays a key role in the occurrence of tablet defects. For instance, convex tablets are more prone to capping than concave tablets [20].
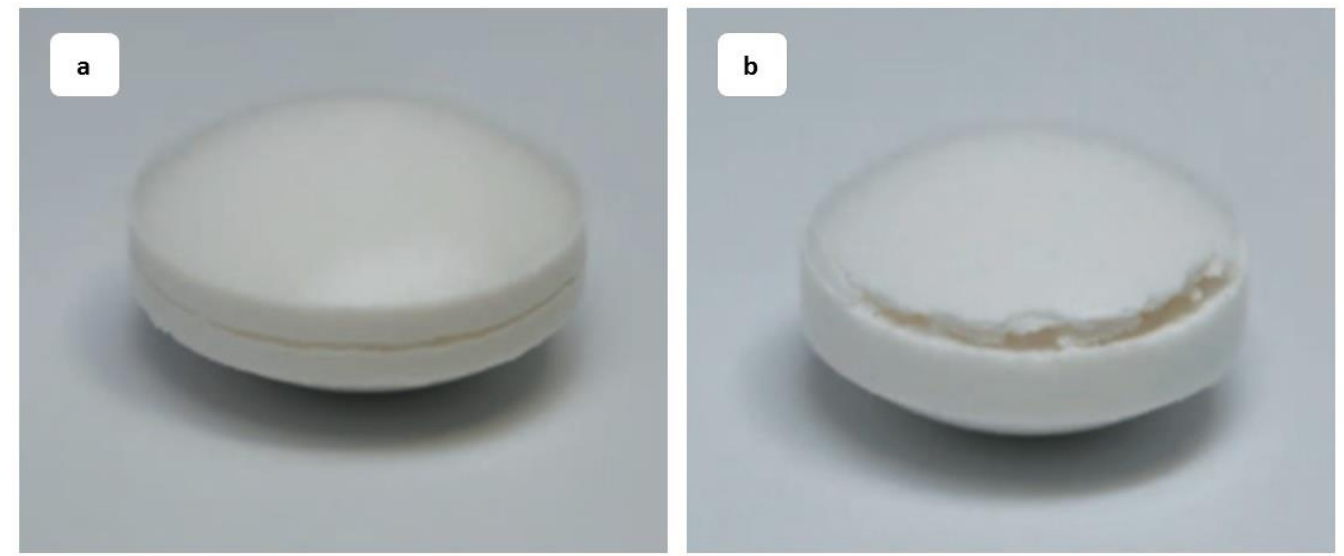

Fig. 1: a) Lamination, a defect exhibiting cracks on the cylindrical part of the tablet geometry; b) Capping, a defect occurring at the junction between the cylindrical part and the convex part of the tablet geometry

\section{Material attributes and process parameters for multi-tableting}

\section{Material mechanical properties}

The proper selection of excipients plays a vital role in the design of high-quality multilayered tablets; hence, the selected excipients should have good flowability, compressibility, compactibility and tabletability. For proper tablet compression, tablets should be plastic and undergo permanent deformation, also exhibit a certain degree of brittleness. Hence, in case of bilayer tablets, it is preferable to choose brittle materials, which potentially can give a sufficient interfacial bonding strength to the bilayer tablets in order to withstand mechanical shocking during production, packing and shipping [28].

The minimum stress level of a material that is required to deform plastically is defined as the yield stress, i.e., pressure as in the case of tableting. It clearly explains the material resistance to densification [28]. The most common method to characterize material plasticity and brittleness by measuring the yield stress or pressure, which can be calculated as the reciprocal of the slope $K$ in the Heckel equation, as shown in (equation 1):

$$
\frac{1}{(1-\mathrm{E})}=\mathrm{K} \log \mathrm{P}+\mathrm{A}(\mathrm{Eq} .1)
$$

Where $\mathrm{E}$ is the tablet porosity, $K$ and $\mathrm{A}$ are constants related to the material under the compaction process, and $\mathrm{P}$ is the compaction pressure in megapascal unit (MPa) [29].

Studies have clearly shown that the yield pressure of plastic materials falls in the range of $40-135 \mathrm{MPa}$. Above this range, the main consolidation mechanism is particle fragmentation and materials are considered as brittle [30-32].

Kottala et al. [18] studied the physicomechanical properties of materials used in the manufacturing of multilayered tablets and concluded that multilayered tablets prepared with brittle materials, such as lactose monohydrate and dicalcium phosphate in each individual layer showed stronger interfacial bonding strength in comparison with other plastic as microcrystalline cellulose, elastic (e. g., sodium starch glycolate) or binary mixtures of plastic/elastic/brittle materials, due to minimization of elastic mismatching between the adjacent layers within the multilayered tablets. On the other hand, the weakest interfacial bonding strength is observed when plastic materials are incorporated in each individual layer. Additionally, when the materials used in the formation of the first layer is more elastic, the tension introduced into the system weakens the strength of multilayered tablets and leads to delamination upon coming off the die [18]. The lack of flexibility of brittle materials significantly reduces particle deformation and fracture on the first layer of tablets, and thus adequate porosity and surface area are resulted for facilitating mechanical interlocking between particles in each individual layer [33].

Powder flow behavior can deeply affect the manufacturing efficiency and product quality of multilayered tablets. Briefly, flowability is the relative movement of bulk of powder particles among unbound or free powders, or along the container wall surface [34]. The degree of flowability is determined by a force balance between particle forces promoting flowability and particle forces preventing flowability [35]. External or gravitational mechanical forces promote the powder flowability and are influenced by several factors, such as the inclination of the powder bed, particle mass and true density. On the contrary, surface interactions and frictions, adhesive and cohesive forces prevent the powder flowability. The extent of these forces mainly depends on both chemical and physical particle properties, such as particle morphology and size distribution [36, 37], moisture content [38], and surface chemical composition [39]. Effective control of flowability relies on the understanding of these aforementioned factors. Materials used in the preparation of multilayered tablets should have good flow properties and handling characteristics.

\section{Lubrication}

Lubrication also plays a significant role in determining the interfacial bonding strength of multilayered tablets. Tye et al. [40] studied the effect of lubricant type and concentration on the interfacial bonding strength of multilayered tablets and concluded that polymeric materials are more pronounced than brittle materials. Moreover, the interfacial bonding strength of multilayered tablets decreases with increasing the concentration of lubricant (e. g., magnesium stearate) [18]. In another relevant study performed 
by Sugisawa et al. [41] suggested that increasing the lubricant's concentration deteriorated the tablet surface roughness, which conferred a decline of interfacial interactions between layers. Alternatively, Yamamura et al. [42] studied the effect of external lubrication, where an external lubricant was sprayed onto the punches and dies and concluded that the external lubrication can increase the crushing strength of monolayer tablets by $40 \%$ without prolonging the corresponding tablet disintegration and dissolution. Hence, the external lubrication possesses some advantages for monolayer tablets, it potentially can be applied to multilayered tablets. However, further external lubrication studies are needed for the proof of concept.

\section{Layer weight control, ratio, and sequence}

In order to obtain an acceptable drug content uniformity, the layer with the lowest drug dose should be compressed first. Hence, it is preferable to have a certain level of weight similarity between the adjacent layers in order to obtain multilayers with acceptable physical and mechanical properties, as well as similar compaction profiles. However, it is often not possible to maintain a similar weight ratio between individual layers for either formulation or therapeutic reasons $[17,43]$. On the other hand, the ratio between individual layers and the sequence of their arrangements plays a key role in reducing the potential of intralayer capping and interlayer delamination, as in the case of bilayer tablets, where the optimal weight ratio between individual layers is $1: 1$ or $1: 2$, and sometimes it extends to $1: 3$ or even $1: 4[16,17]$. Experimentally, it is preferable to firstly compress the layer with the lowest drug dose. However, until now, there are no available tablet presses that can precisely compress the first layer with low drug content. Thus, there is no possibility to avoid common problems associated with the first layer compression. It is also preferable to use materials with a higher fragmentation tendency to formulate the first layer, and materials with a greater elastic-plastic deformation capacity in formulating other layers $[40,43]$.

Alkseil et al. [44] studied the effect of porosity on the bonding strength between the adjacent layers and concluded that when the first layer had low porosity, the bonding with the second layer became more difficult due to the tensile strength $(\sigma)$ of the first layer was greater than the tensile strength of the interface $\left(\sigma_{\text {layer }}>\sigma_{\text {interface }}\right)$. Briefly, they prepared bilayer tablets containing microcrystalline cellulose (plastic material) in both layers and compacted with initial forces of $2 \mathrm{kN}$ and $4 \mathrm{kN}$ and observed that once the second layer compression force leveled up to $18 \mathrm{kN}$, tablets failed in the first layer rather than the interface ( $\sigma_{\text {layer }}<\sigma_{\text {interface }}$ ), indicating a change in the mode of failure from the interlayer ( $\left.\sigma_{\text {interface }}\right)$ to intralayer ( $\left.\sigma_{\text {layer }}\right)$. This finding was in accordance with other reported work by Lacombe [45]. Alternatively, bilayer tablets containing microcrystalline cellulose in the first layer and starch (elastic material) in the second layer showed weak bonding in which tablets were split a part along the interface either during pre-or postcompaction process. Moreover, the surface roughness of the first layer containing microcrystalline cellulose was significantly reduced, indicating a decrease in inter-particulate cohesion and mechanical interlocking between the adjacent layers [44]. Inman et al. [33] declared that due to the rigid nature of brittle materials (higher Young's modulus in comparison with plastic materials), the deformability capacity of brittle material fine particles on the initial layer was significantly reduced, resulting a substantial roughness on the surface, which promoted attractive sites for mechanical interlocking. For plastic deformable materials (microcrystalline cellulose and sodium chloride), the bonding between the adjacent layers decreased with decreasing the interfacial surface roughness, while in the case of fragment materials (lactose and calcium phosphate), the bonding between the adjacent layers was insensitive to roughness, hence the area of contact was maximized between the fragmented particles after their initial fracture.

\section{Interlayer adhesion strength}

Interlayer adhesion strength is a key factor of the technological processes of multilayered tablets which is initially considered when preparing each layer separately. The central layer of tablet (core tablet) is first prepared during pre-compression stage, followed by upper and lower layers (outer layers), which are subsequently compressed into the central layer $[46,47]$. Hence, the central layer is a compressed tablet, covered by outer layers, the drug release rate is mainly controlled by the outer layers [48]; therefore, a sufficient interlayer adhesion strength is difficult to achieve, but it is necessary to maintain the physical integrity of multilayered tablets [16]. Furthermore, in order to improve the strength of adhesion, low lubricant content, low compression force to develop the core, and high compression force to develop the outer layers are necessary and advantageous [12].

\section{Compaction and compression processes}

The ideal compaction properties of each individual layer are often determined by establishing the compactibility curve by plotting compact strength (tensile strength) versus solid fraction (porosity). Compact strength is usually expressed as tensile strength, which fundamentally measures the mechanical strength of compacted material and the tablet geometry, and can be calculated by Fell and Newton's equation [30], using the following (equation 2) [49]:

$$
\sigma=\frac{2 \mathrm{~F}}{\pi \mathrm{DH}}(\mathrm{Eq} .2)
$$

Where, $\sigma$ is the tensile strength $\left(\mathrm{Kg} / \mathrm{cm}^{2}\right), \mathrm{F}$ is the breaking force $(\mathrm{Kg}), \mathrm{D}$ is the tablet diameter $(\mathrm{cm})$, and $\mathrm{H}$ is the tablet thickness (cm). This equation is only applied to cylindrical tablets. If tablets are right circular cylinders with a three-point flexure, the tensile strength can be calculated by using the following (equation 3) [50]:

$$
\sigma=\frac{3 \mathrm{FL}}{2 \mathrm{DH}^{2}} \text { (Eq. 3) }
$$

Where, $\mathrm{L}$ is the distance between supports, and the other terms are as defined above.

Compression force also plays a significant role in determining the strength and interfacial adhesion between layers, thus contributing to the mechanical integrity of multilayered tablets [33]. Therefore, it is necessary to determine the optimum compression force in order to form multilayered tablets with desirable mechanical properties. Hence, the compression force is the most crucial parameter in optimizing the first layer of multilayered tablets, which in turn greatly affects the formulation of other adjacent layers [51]. In addition to other physical parameters as the compression pressure and punch speed, which also profoundly affect the compatibility and resistance to compressibility into the die [10]. Yang et al. [52] concluded that an increase in the punch speed between 50 to $500 \mathrm{~mm} / \mathrm{sec}$ significantly decreased the porosity on each individual layer. Generally, the compression force of the first layer is set to be around 2-18 kN in order to lamp the powders/granules to diminish the volume and create more space for depositing the second layer [43]. In fact, high compression forces may lead to an increase the tensile strength and decrease surface roughness [43]. Alternatively, surface smoothness of the first layer may also lead to an increase the possibility of delamination by limiting the intramolecular adherence between the adjacent layers [16]. Interestingly, Karehill et al. [53] studied the relation between the pressure force applied to the first layer of a brittle material and the tensile strength of multilayered tablets and concluded that the increase in the pressure force applied to the first layer of a brittle material led to a reduction in the surface adhesion and bonding between the adjacent layers, and subsequently decreased the tensile strength of multilayered tablets. Furthermore, bilayer tablets made of brittle materials showed no delamination even at relatively higher compression forces applied to the first layer [17]. On the contrary, tablets made by polymeric materials showed a decrease in the interfacial bonding strength when higher compression forces were applied to the first layer [18]. Therefore, the level of the compression force is fundamentally essential to determine the surface roughness of the first layer, which reflects the interfacial bonding strength between layers. On the other hand, the turret speed has a significant effect on determining the strengths of multilayered tablets, where tablet crushing strength increases gradually with increasing the turret speed $[10,54]$. Apart from the above mentioned, dwell time (contact time between the punch head and compression roller) also considers a critical factor and should be determined in every single compression stage to minimize the possibility of layer separation and capping [55]. These parameters in a specific range have no effect on content 
uniformity and release rate from multilayered tablets. However, the drug release rate and retardation time are augmented with increasing the compression force till reaching the optimum compression force, where no more changes in porosity or physicomechanical properties of tableting materials.

\section{Effect of moisture on compaction and compression processes}

Tablets made of hygroscopic materials will respond to the relative humidity of the surrounding environment, either by absorbing or desorbing of moisture content into or out of their porous structures [56]. Moreover, if tablets contain microcrystalline cellulose, hydroxypropyl methylcellulose, starch, sodium starch glycolate, polyvinylpyrrolidone, crospovidone and colloidal silicone dioxide, moisture can easily penetrate the tablet compact through the microstructural cervices within the table compact. Hence, the presence of moisture in the tablet compact leads to layer expansion and changes in the Young's modulus of elasticity [17, 56]. Furthermore, any changes in layer dimensions will ultimately weaken the interface between the adjacent layers and cause timedependent delamination. Therefore, it is preferable to use materials that are in equilibrium with the manufacturing area and should be tightly stored in air-tight containers.

\section{Effect of storage conditions on the physical stability of} multilayered tablets

Physical stability of multilayered tablets on storage has a significant effect on their quality attributes, such as tensile strength, interlayer adhesion strength, crushing strength, friability, disintegration, and dissolution [18]. For instance, bilayer tablets prepared with microcrystalline cellulose in the first layer and lactose in the second layer showed a decrease in the tablet interfacial strength with increasing the humidity and storage time, while bilayer tablets prepared with lactose in both layers showed an increase in the interfacial strength due to the formation of solid bridges between particles during storage [56]. Klinzing and Zavaliangos [57] studied the effect of humidity on the interfacial bonding strength of bilayer tablets composed of microcrystalline cellulose and dicalcium phosphate and concluded that transient moisture diffusion through bilayer tablets was responsible for the reduction of interfacial bonding strength in both high and low humidity conditions.

\section{Cross-contamination between the adjacent layers}

In order to remove the cross-contamination between the adjacent layers and get a clear separation, scraper plates are located before and after each die fill to remove any residual powder dust resulted from compression processes. Hence, bilayer tablet presses are often equipped with suction nozzles or dust extractors to remove these fine powders or granules [58].

\section{Bilayer tablet compression machines}

The Korsch XM-12 (Korsch AG, Berlin, Germany) is a small-scale industrial bilayer tablet press which is ideally suited for product development, small-scale and pilot-scale production for clinical trials. The bilayer execution, single-layer conversion kit, and exchangeable turret capability exclusively offer unprecedented flexibility. The retractable second layer feeder allows automated first layer sampling at different production speeds. Both feeders use zero clearance technology and are installed with an integrated dust extraction manifold, which cleans the die table and eliminates any potential for cross-contamination. The Korsch XM-12 bilayer tablet press provides high accessibility to the compression and cleaning zones [59].

Other commonly used industrial bilayer tablet presses are RoTab Bilayer 2.0 (kg-pharma, Scharbeutz, Germany), KTP 720X (Romaco Kilian, Karlsruhe, Germany), Kilian's Synthesis 500 Bilayer (Romaco Kilian, Karlsruhe, Germany), FlexiTab (Syntegon, Waiblingen, Germany), PR-LT Laboratory Tablet Press (PTK-GB Limited, Staffordshire, England), FE55 (Fette Compacting, New Jersey, USA), Oystar Manesty Xpress (Oystar, New Jersey, USA), Kikusui Libra2-2L (Kikusui, Via Dell'Artigianato, Muggio, Italy), Chamunda Duo Press (Chamunda Pharma, Ahmedabad, India), EP 200 L (Parle Elizabeth Tools Pvt. Ltd, Ahmedabad, India), and Piccola Bi-Layer (Riva S. A., Génova, Ciudadela, Argentina).

The preparation steps of bilayer tablets are shown in fig. 2 .
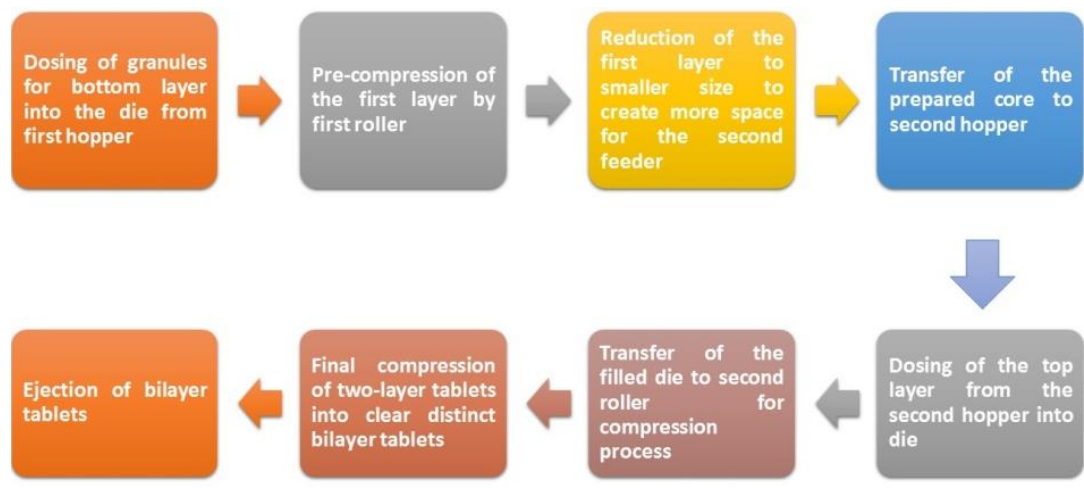

Fig. 2: A schematic representation of the preparation procedure for bilayer tablets

\section{Preparation technologies of bilayer tablets OROS® push-pull technology}

It consists of two or three layers in which one or more layers are drug layers and other layers are push layers. The drug layer mainly consists of the poorly water-soluble drug and bulking agents, acting as suspending and osmotic agents. A semipermeable membrane surrounds the tablet core, as shown in (fig. 3) $[60,61]$.

\section{L-OROS tm technology}

Alza developed L-OROS system, where a lipid soft gel product containing the drug substance in the dissolved state is initially prepared, then coated with a barrier layer, followed by an osmotic push layer and a semi-permeable membrane, drilled with an exit orifice, as shown in (fig. 4) [62-64].

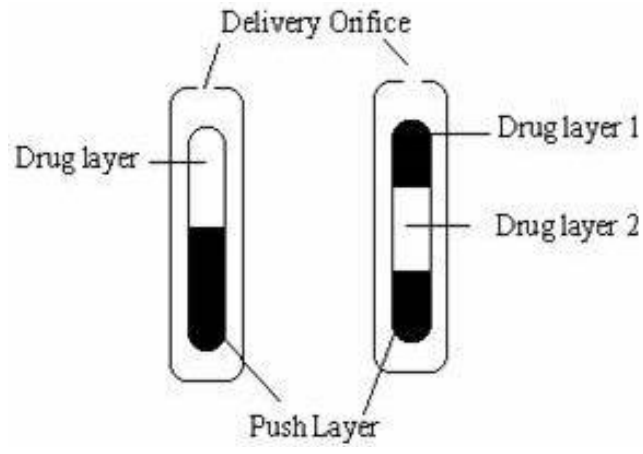

Fig. 3: Bilayer OROS $®$ push-pull technology 


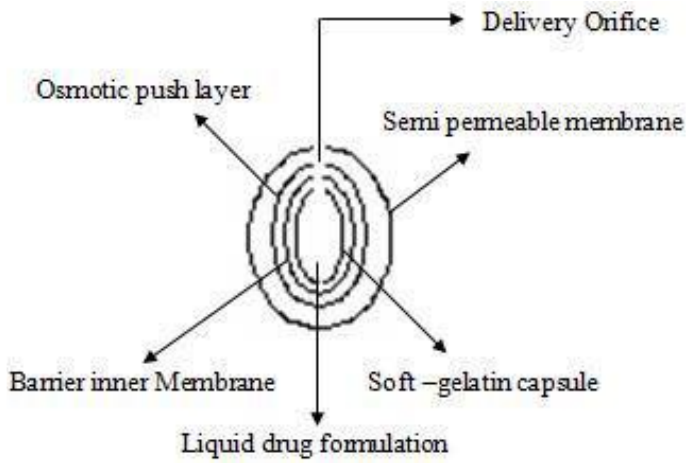

Fig. 4: Bilayer L-OROS tm technology

\section{EN SO TROL technology}

Shire laboratory-developed EN SO TROL technology based on identification and incorporation of an enhancer into controlledrelease systems (fig. 5) [65].

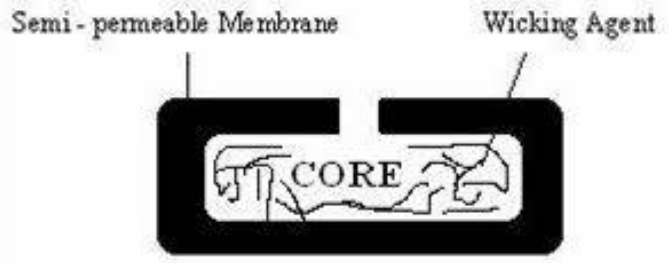

Fig. 5: Bilayer EN SO TROL technology

\section{DUROS technology}

Alza corporation developed DUROS technology, which is considered as an implantation technique for the transmission of therapeutic substances, such as peptides, proteins, and other biological substances. It refers to as a miniature drug dispensing system that releases the drug substance continuously in a concentrated form for a long period of time. As shown in (fig. 6), it consists of an outer cylindrical titanium alloy reservoir, which protects the drug substance from enzymes and makes it resistant to human tissues for a long time $[66,67]$.

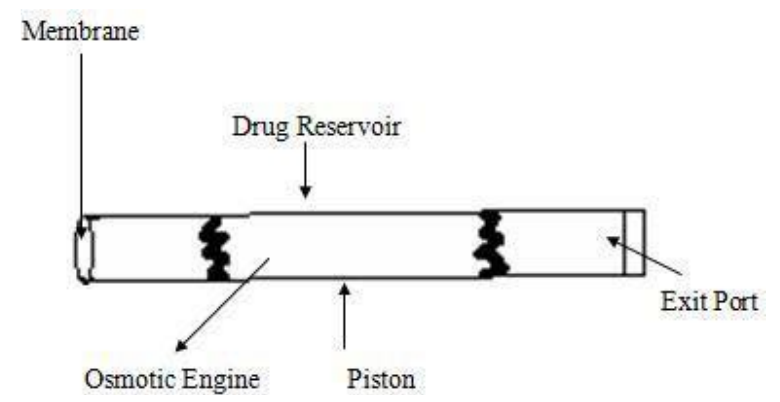

Fig. 6: Bilayer DUROS technology

\section{DUREDAS $^{T M}$ technology (Dual release drug delivery system)}

Elan corporation developed DUREDAS technology, which provides a combination drug release pattern, i.e., immediate, and sustainedrelease pattern. In a brief, this technology produces tablets through two independent direct compression stages, which combine the immediate release layer with the hydrophilic layer in a single tablet dosage form, resulting a controlled hydrophilic matrix system that gradually absorbs liquid from the gastrointestinal tract (GIT). Upon absorption, it turns into a sticky, permeable gel, which primarily acts as a hinderance between the dosage form and the adjacent fluid. As the gel expands, more the surrounding fluid penetrates the drug substance and dissolves it $[68,69]$.

\section{Geminex technology}

This technology can greatly help in increasing the therapeutic effectiveness of active substances and minimizing their side effects. It is characterized by delivering one or more active substances having different drug release pattern through a single dose [70].

\section{Programmable oral drug absorption system (PRODAS)}

It is also known as multi particulate drug technology, developed by Elan corporation, which encapsulates mini-tablets of controlled drug release profiles, ranging in size from 1.5 to $4 \mathrm{~mm}$. This technology is a combination of multiparticulate and hydrophilic matrix tablet technologies and is mainly used for providing a drug combination in a single dose [71, 72].

\section{Erodible molded multilayered tablets}

This technology is developed by Egalet Corporation and solves major problems of drug instability. it is advantageous over other technologies in showing high accuracy, reproducibility, and low production costs. It consists of a coat and a polymeric matrix. The drug release from the erodible molded multilayered tablets is primarily governed by the erosion of the polymeric matrix and controlled by the proper selection of coating materials and ideal design of the matrix geometry. The drug release from the erodible molded multilayered tablets follows zero-order release kinetics, hence the coat is biodegradable and has low water permeability [73].

\section{Geomatrix technology}

This technology is designed for preparing multilayered tablets with controlled loading and release characteristics. Hence, the active ingredient is present inside a matrix core surrounded by one or more barrier layers in order to avoid any possible contact between the core and dissolution medium [74].

\section{Gluing pills technology (GPT)}

Gluing Pills Technology (GPT) relies on blending APIs with other excipients, then compacting them into monolayer tablets. Both are glued together via the GPT, using a viscous solution of either gelatin or PVP (polyvinylpyrrolidone) K-90 as gluing agents. Factors that should be detected on the deformation behavior of blends are elastic recovery, tensile strength, and porosity of monolayer tablets. The type of gluing agent is a critical factor in applying GPT. Raman microscopy analysis is successfully applied to qualitatively assess the function of gluing layer as a barrier to cross-contamination between two monolayer tablets [75].

\section{Bilayer tablet characterization}

\section{Transmission raman spectroscopy (TRS)}

Raman spectroscopy can be used for microstructural characterization of drug delivery systems, as well as to understand drug-excipient interactions in the formulation. Raman chemical imaging has been utilized to determine the size distribution of API microparticles and to determine the API distribution homogeneity in a composite formulated tablet [76]. Transmission Raman Spectroscopy (TRS) has become an increasingly applied technology in the analysis of pharmaceutical tablets for quality control purposes, developing formulation and process understanding. Bilayer tablet represents an unusually challenging situation based on its complex composition. This quantitative model of analysis aimed for the prediction of API content in multilayered tablets [77].

\section{Powder particle properties}

Particle size distribution of powder mixtures is evaluated with a laser diffractometer. The particle shape is estimated by particle roundness. Images of particles are taken with an optical microscope and digitally processed in order to calculate the particle roundness according to the following (equation 4): 


$$
\mathrm{R}=\frac{4 \mathrm{~A}}{\pi \mathrm{l}_{\max }^{2}}(\mathrm{Eq} .4)
$$

Where, $A$ represents the projected area and $l_{\max }$ represents the maximum length of the single-particle.

\section{Powder flow properties}

Flow properties of powder mixtures are determined by the calculations of Hausner ratio (equation 5) and Carr's compressibility index (equation 6).

$$
\begin{aligned}
\text { Hausner ratio } & =\frac{\text { Tapped density }}{\text { Bulk density }} \quad(\text { Eq. 5) } \\
\text { Carr's compressibility index } & =\frac{\text { (Tapped density-Bulk density) }}{\text { Tapped density }} \times 100 \text { (Eq.6) }
\end{aligned}
$$

\section{Moisture content of powder mixtures}

Moisture content of powder mixtures is measured gravimetrically by a thermal balance.

\section{Weight uniformity}

The tablets comply with the test if not more than 1 individual mass is outside the limits of $85-115 \%$ of the average mass. The tablets fail to comply with the test if more than 1 individual mass is outside these limits, or if 1 individual mass is outside the limits of $75-125 \%$ of the average mass.

\section{Hardness test}

The crushing strength test was carried out for 10 tablets using the hardness tester. The diametral tensile strength (DTS) of tablets was calculated using (equation 2) [49].

\section{Friability test}

Friability test is performed for both single and multilayered tablets. For multilayered tablets, a friability test is used with the intent of investigating the delamination tendency of multilayered tablets, after 100 rotations per min, the number of delaminated tablets is counted according to the following (equation 7) [78].

$$
\text { Friability }=\frac{\left(\mathrm{w}_{0}-\mathrm{w}_{\mathrm{f}}\right)}{\mathrm{w}_{0}} \times 100 \text { (Eq. 7) }
$$

Where, $W_{0}$ is the initial weight of tablets, and $W_{f}$ is the final weight of tablets.

\section{Thickness and diameter}

Tablet thickness and diameter are determined by using a micrometer caliper (vernier scale) in millimetre unit $[79,80]$.

\section{In vitro disintegration time}

Disintegration time is evaluated by using USP tablet disintegration tester apparatus type I (basket mode). The disintegration medium is often 900 $\mathrm{ml}$ of purified water kept at a temperature of $37 \pm 0.5{ }^{\circ} \mathrm{C}$. The time required for complete disintegration is measured in $\min [79,80]$.

\section{In vitro and comparative dissolution}

Four dissolution medias are typically used for the evaluation of in vitro and comparative dissolution, namely hydrochloric acid $0.1 \mathrm{~N}(\mathrm{pH} 1.2)$, acetate buffered solution ( $\mathrm{pH} 4.5$ ), phosphate-buffered solution ( $\mathrm{pH}$ 6.8), and phosphate-buffered saline ( $\mathrm{pH}$ 7.4). Dissolution tester equipped with USP apparatus type II (paddle mode) is most often applied for dissolution experimental evaluation. All dissolution tests are usually conducted in $900 \mathrm{ml}$ of each dissolution media kept at a constant temperature of $37^{\circ} \mathrm{C} \pm 0.5^{\circ} \mathrm{C}$. Comparative dissolution studies are mainly carried out against the reference product. In vitro drug dissolution profiles are subsequently compared with the reference product using the similarity (f2) and difference (f1) factors, as described by the following (equation 8) and (equation 9), respectively [79, 80]:

$$
\begin{gathered}
\mathrm{f}_{2}=50 \log \left\{\left[1+\frac{1}{\mathrm{n}} \sum_{\mathrm{t}=1}^{\mathrm{n}}\left(\mathrm{R}_{\mathrm{t}}-\mathrm{T}_{\mathrm{t}}\right)^{2}\right]^{-0.5} \times 100\right\} \text { (Eq. 8) } \\
\mathrm{f}_{\mathrm{t}}-\left\{\sum_{\mathrm{t}=1}^{\mathrm{n}}\left|\mathrm{R}_{\mathrm{t}}-\mathrm{T}_{\mathrm{t}}\right| \sum_{\mathrm{t}=1}^{\mathrm{n}} \mathbf{R}_{\mathrm{t}}\right\} \times 100 \\
\text { (Eq. 9) }
\end{gathered}
$$

Where, $\mathrm{n}$ represents the number of sampling time points, $\mathrm{R}_{\mathrm{t}}$ represents the mean percent dissolved of the reference product up to each time point, $\mathrm{T}_{\mathrm{t}}$ represents the mean percent dissolved of bilayer tablets up to each time point. $\mathrm{f}_{2}$ represents a logarithmic transformation of the sum-squared error of the difference between the reference and test over all time points. For similar dissolution profiles, $f_{2}$ (similarity factor) values should be higher than 50 . On the other hand, $f_{1}$ defines the percent difference between two curves at each time point and represents a measurement of relative error between curves. $f_{1}$ (difference factor) values should be lower than 15 $[79,80]$.

\section{Analysis of dissolution data}

\section{Dissolution efficiency (DE)}

Dissolution efficiency (DE) represents the area under the dissolution curve within a time range of $\left(\mathrm{t}_{1}-\mathrm{t}_{2}\right)$, and can be measured by using the following (equation 10) [81, 82]:

$$
\mathrm{DE}=\frac{\int_{t_{1}}^{t_{2}} y \mathrm{~d} t}{y_{100} \times\left(t_{2}-t_{1}\right)} \times 100
$$

Where y represents the percentage of drug dissolved at the time $(\mathrm{t})$.

Formulations are considered equivalent when the difference in between their dissolution efficiencies and the reference product is within the range of $\pm 10 \%$ [83].

\section{Mean dissolution time (MDT)}

Mean dissolution time (MDT) can be further calculated from the dissolution data by using the following (equation 11) [82-84]:

$$
\mathrm{MDT}=(\mathrm{n} / \mathrm{n}+1) \mathrm{K}^{(-1 / \mathrm{n})}
$$

Where, $\mathrm{n}$ represents the release exponent, $\mathrm{K}$ represents the release rate constant.

A higher MDT value refers to higher retaining efficacy of the polymer [83].

\section{Drug release kinetics}

For the evaluation of drug release kinetics, the data obtained from in vitro drug dissolution are applied to the following mathematical models.

\section{Zero-order release kinetics}

In zero-order release kinetics, the cumulative amount of drug release is directly proportional to time, as described by the following (equation 12):

$$
\left.\mathrm{C}=\left(\mathrm{K}_{0} \cdot \mathrm{t}\right) \quad \text { (Eq. } 12\right)
$$

Where, $\mathrm{K}_{0}$ represents the zero-order rate constant expressed as concentration per time and $t$ represents the time per $h$.

\section{First-order release kinetics}

It is expressed as log cumulative percentage of drug remaining or undissolved versus time, as described by the following (equation 13) $[82,85]$ :

$$
\log C=\left(\log C_{0}-K_{t} / 2.303\right) \quad(E q .13)
$$

Where, $\mathrm{C}$ represents the amount of drug undissolved at time, $\mathrm{C}_{0}$ represents the drug concentration at $t$ equals to 0 , and $\mathrm{k}_{\mathrm{t}}$ represents the corresponding release rate constant.

\section{Higuchi square root release model}

It is expressed as the cumulative percentage of drug release versus square root of time, as described by the following (equation 14) [82, 86]:

$$
\mathrm{Q}=\left(\mathrm{K}_{\mathrm{H}} \cdot \mathrm{t}^{\frac{1}{2}}\right)(\text { Eq. 14) }
$$

Where, $\mathrm{Q}$ represents the amount of drug dissolved at time, $\mathrm{K}_{\mathrm{H}}$ represents the Higuchi constant. 


\section{Hixson-crowell cube root release model}

It is expressed as the cube root of the initial concentration minus the cube root of the percentage of drug remaining or undissolved in the tablet system versus time, as described by the following (equation 15) $[82,87]$ :

$$
\left(\mathrm{Q}_{0}{ }^{\frac{1}{3}}-\mathrm{Q}^{\frac{1}{3}}=\mathrm{K}_{\mathrm{HC}} \cdot \mathrm{t}\right) \text { (Eq. 15) }
$$

Where, $Q_{0}$ represents the initial amount of the drug in tablets, $Q_{t}$ represents the amount of drug release at time, and $\mathrm{k}_{\mathrm{HC}}$ represents the rate constant for the Hixson-Crowell cube root model.

\section{Korsmeyer-peppas equation}

It is a semi-empirical equation relating exponentially the drug release to the elapsed time, as described by the following (equation 16) $[82,88]$ :

$$
\mathrm{Q} / \mathrm{Q}_{0}=K \mathrm{t}^{\mathrm{n}} \text { (Eq. 16) }
$$

Where $\mathrm{Q} / \mathrm{Q}_{0}$ represents the fraction of drug released at time, $\mathrm{k}$ represents the constant comprising the structural geometric characteristics, $\mathrm{n}$ represents the diffusion exponent that depends on the release mechanism.

If $\mathrm{n}$ equals 0.45 , the release mechanism follows Fickian diffusion (case I); $0.45<\mathrm{n}<0.89$, the release mechanism follows non-Fickian (anomalous case); while if $n>0.89$, the release mechanism follows super case II transport. Case II transport depends on the erosion of polymeric chains, while non-Fickian (anomalous case) depends on a combination of both diffusion and erosion mechanisms $[82,88]$.

\section{Scanning electron microscopy (SEM)}

Morphology of bilayer tablets is visualized by scanning electron microscope (SEM). Cross-section samples of the prepared tablets are attained by scalpel-slicing of tablets, then sticked to a brass stub by using an adhesive tape, followed by coating under a vacuum with a thin layer of gold $(\sim 150 \AA)$ for a couple of seconds, then measured microscopically [80].

\section{Differential scanning calorimetry (DSC)}

Thermal analysis is performed by using differential scanning calorimetry (DSC). Bilayer tablets, pure drug substances and excipients are sealed into aluminium pans and heated over a temperature ranging from 20 $300{ }^{\circ} \mathrm{C}$ at a linear heating rate of $10^{\circ} \mathrm{C}$ min-1 under nitrogen (N2) gas. Each drug substance has a characteristic peak. The absence of this peak in the DSC thermogram indicates that the drug substance is molecularly dispersed in the tablet matrix system [80].

\section{X-Ray powder diffraction (XRPD)}

Crystallinity of the drug substances in bilayer tablets is evaluated by using x-ray diffractometer. XRPD measurements are performed at the room temperature using a $\mathrm{Cu}$ anode and a graphite monochromator, operated at a voltage of $35 \mathrm{kV}$ and a current-voltage of $20 \mathrm{~mA}$. Bilayer tablets are evaluated by the $2 \theta$ diffraction angle at a range of 5-50 ${ }^{\circ}$, the process parameters were set as scan-size of $0.02^{\circ}(2 \theta)$, and a scan step-time of $25 \mathrm{~s}$. Possible changes in the characteristic peaks of the drug substances indicates that the transformation of the drug substances from crystalline to amorphous forms [82].

\section{Stability studies}

The powder mixtures or granules are stored in a desiccator over calcium chloride $\left(\mathrm{CaCl}_{2}\right)$ at $0 \%$ relative humidity at room temperature $\left(25^{\circ} \mathrm{C}\right)$, while the compressed tablets are packed in $\mathrm{PVC} / \mathrm{PVDC} / \mathrm{Al}$ blisters or $\mathrm{Al} / \mathrm{Al}$ blisters, and stored at $40{ }^{\circ} \mathrm{C} / 75 \% \mathrm{RH}$ as suggested by International Council for Harmonization (ICH) guideline for accelerated stability studies. Data obtained from accelerated stability studies are plotted based on Arrhenius equation for determining the optimum shelf life of bilayer tablets at toom temperature $[22,89]$.

Examples of commercially available bilayer tablets approved by FDA are listed in (table 1).

\begin{tabular}{|c|c|c|c|c|}
\hline Active ingredients & Strength & Proprietary name & Approval date & Manufactured by \\
\hline Guaifenesin & $1.2 \mathrm{gm}$ & Mucinex & Dec 18, 2002 & RB Health US LLC \\
\hline Dextromethorphan Hydrobromide & $60 \mathrm{mg}$ & Mucinex DM & Apr 29, 2004 & RB Health US LLC \\
\hline Guaifenesin & $1.2 \mathrm{gm}$ & & & \\
\hline Pseudoephedrine Hydrochloride & $120 \mathrm{mg}$ & Mucinex D & Jun 22, 2004 & RB Health US LLC \\
\hline Guaifenesin & $1.2 \mathrm{gm}$ & & & \\
\hline Doxazosin Mesylate & $8 \mathrm{mg}$ & Cardura XL & Feb 22, 2005 & Upjohn US 1 LLC \\
\hline Desloratadine & $2.5 \mathrm{mg}$ & Clarinex-D $12 \mathrm{~h}$ & Feb 1, 2006 & Merck Sharp and Dohme Corp \\
\hline Pseudophedrine Sulphate & $120 \mathrm{mg}$ & & & \\
\hline Efavirenz & $600 \mathrm{mg}$ & Atripla & Jul 12, 2006 & Gilead Sciences LLC \\
\hline Emtricitabine & $200 \mathrm{mg}$ & & & \\
\hline Tenofovir Disoproxil Fumarate & $300 \mathrm{mg}$ & & & \\
\hline Glimepiride & $2 \mathrm{mg}$ & Duetact & Jul 28, 2006 & Takeda Pharmaceuticals USA Inc \\
\hline Pioglitazone $\mathrm{HCl}$ & $30 \mathrm{mg}$ & & & \\
\hline Cetrizine $\mathrm{HCl}$ & $5 \mathrm{mg}$ & Zyrtec-D $12 \mathrm{~h}$ & Nov 9, 2007 & Johnson and Johnson Consumer Inc Mcneil \\
\hline Pseudoephedrine $\mathrm{HCl}$ & $120 \mathrm{mg}$ & & & Consumer Healthcare Division \\
\hline Naproxen Sodium & $500 \mathrm{mg}$ & Treximet & Apr 15, 2008 & Currax Pharmaceuticals LLC \\
\hline Sumatriptan Succinate & $85 \mathrm{mg}$ & & & \\
\hline Metformin $\mathrm{HCl}$ & $1 \mathrm{gm}$ & Janumet XR & Feb 2, 2012 & Merck Sharp and Dohme Corp \\
\hline Sitagliptin Phosphate & $100 \mathrm{mg}$ & & & \\
\hline Levetiracetam & $1.5 \mathrm{gm}$ & Elepsia XR & Dec 20, 2018 & Tripoint Therapeutics \\
\hline Dolutegravir Sodium & $50 \mathrm{mg}$ & Dovato & Apr 8, 2019 & Viiv Healthcare Co \\
\hline Lamivudine & $300 \mathrm{mg}$ & & & \\
\hline
\end{tabular}

Table 1: Commercially available bilayer tablets in U. S. market according to the FDA orange book [90]

\section{D printed multilayered tablets}

Three-dimensional printing (3DP) has demonstrated great potential for multi-material fabrication because of its capability for printing bespoke and spatially separated material conformations. For the first time, 3D printer was successfully modified to enable multi-resin printing for the fabrication of bespoke and tailored polypills containing six different active ingredients [91]. The use of computeraided design (CAD) in 3DP technology allows the manufacturing of drug formulation with the desired release rate and pattern.
Currently, the most applicable 3DP technologies in the oral drug delivery system are inkjet printing method, fused deposition method, nozzle-based extrusion system, Zip dose method, and stereolithographic 3D $[92,93]$.

Possible future prospects in the development of multilayered tablets

Recently, fixed-dose combination drugs are becoming increasingly popular, particularly as lifecycle management strategies seeking to 
extend intellectual property and minimizing generic exposure by creating an innovative dosage form [94]. The most recent studies point to new obstacles in the subdivision of modified-release tablets, so multilayered tablets will be a promising alternative for subdivision [95]. Currently, tools required for the production of high-tech machinery, such as multilayer presses have been identified, production gaps have been filled, and the next step will be a joint effort between academy, industry, and regulatory experts to begin implementing these measures in practice [96].

\section{CONCLUSION}

Multilayered tablets are considered as a promising drug delivery system, hence multilayered tablets are useful for providing sequential release of two or more drugs, and also for achieving sustained release profiles. In the case of bilayer tablets, the first layer is designed for immediate release which is referred to as the initial dose and the second layer as the maintenance dose. Currently, many pharmaceutical companies are developing multilayered tablets for several pharmaceutical and therapeutic purposes, as well as for reducing capital investment.

\section{CONSENT FOR PUBLICATION}

Not applicable

\section{ACKNOWLEDGEMENT}

The authors would like to thank Prof. Dr. Hala El-Mesallamy, the Dean of Faculty of Pharmacy, Sinai University Kantra Campus, Dr. Hassan Hassan, Managing Director of IDI Pharmaceutical, and Dr. Hussein Hassan, Chairman of IDI Pharmaceutical for their continued support and guidance.

\section{FUNDING}

No external funding.

\section{AUTHORS CONTRIBUTIONS}

All the authors have contributed equally.

\section{CONFLICTS OF INTERESTS}

The authors reports no conflicts of interest.

\section{REFERENCES}

1. Efentakis M, Peponaki C. Formulation study and evaluation of matrix and three-layer tablet sustained drug delivery systems based on carbopols with isosorbite mononitrate. AAPS PharmSciTech 2008;9:917-23.

2. Vaithiyalingam SR, Sayeed VA. Critical factors in manufacturing multilayered tablets-assessing material attributes, in-process controls, manufacturing process and product performance. Int J Pharm 2010;398:9-13.

3. Nirmal J, Saisivam S, Peddanna C, Muralidharan S, Nagrarajan M. Bilayer tablets of atrovastatin calcium and nicotinic acid: formulation and evaluation. Chem Pharm Bull 2008;56:1455-8.

4. Shiyani B, Gattani S, Surana S. Formulation, and evaluation of bi-layer tablet of metoclopramide hydrochloride and ibuprofen. AAPS PharmSciTech 2008;9:818-27.

5. La Force C, Gentile DA, Skoner DP. A randomized, double-blind, parallel-group, multicenter, placebo-controlled study of the safety and efficacy of extended-release of guaifenesin/pseudoehphedrine hydrochloride for symptom relief as adjunctive therapy to antibiotic treatment of acute respiratory infections. Post Grad Med 2008:120:53-9.

6. Gavate NT, Gondkar SB, Saundaga RS. Multilayer tablet: a new trend in solid dosage forms. World J Pharm Pharm Sci 2013;2:271-84.

7. Qiu Y, Chidambaram N, Flood K. Design, and evaluation of layered diffusional matrices for zero-order sustained-release. J Controlled Release 1998;51:123-30.

8. Yadav G, Bansak M, Thakur N, Khare SP. Multilayer tablets and their drug release kinetic models for oral controlled drug delivery system. Middle-East J Sci Res 2013;16:782-95.

9. Maroni A, Zema L, Carea M, Sangalli ME. Oral pulsatile drug delivery systems. Expert Opin Drug Delivery 2005;2:855-71.
10. More S, Ghodekar S, Rane B, Bavaskar K, Patil M, Jain A. Multilayered tablet: a novel approach for oral drug delivery. Int J Pharm Sci Rev Res 2015;9:872-82.

11. Charman SA, Charman WN. Oral modified-release delivery systems. In: Rathbone MJ, Hadgraft J, Roberts MS. (Eds.) Modified-release drug delivery technology. Informa Healthcare; 2002. p. 1-19.

12. Abdul S, Poddar SS. A flexible technology for modified release of drugs: multi-layered tablets. J Controlled Release 2004;97:393-405.

13. Ozeki Y, Ando M, Watanabe Y, Danjo K. Evaluation of novel onestep dry-coated tablets as a platform for delayed-release tablets. J Controlled Release 2004;95:51-60.

14. Akseli I, Dey D, Cetinkaya C. Mechanical property characterization of bilayered tablets using nondestructive aircoupled acoustics. AAPS PharmSciTech 2010;1:90-102.

15. Klinzing G, Zavaliangos A. Understanding the effect of environmental history on bilayer tablet interfacial shear strength. Pharm Res 2013;30:1300-10.

16. Desai D, Wang J, Wen H, Li X, Timmins P. Formulation design, challenges, and development considerations for fixed dose combination (FDC) of oral solid dosage forms. Pharm Dev Technol 2013;18:1265-76.

17. Abebe A, Akseli I, Sprockel O, Kottala N, Cuitino AM. Review of bilayer tablet technology. Int J Pharm 2014;461:549-58.

18. Kottala N, Abebe A, Sprockel O, Bergum J, Nikfar F, Cuitino A. Evaluation of the performance characteristics of bilayer tablets: part I. Impact of material properties and process parameters on the strength of bilayer tablets. AAPS PharmSciTech 2012;13:1236-42.

19. Sinka IC, Pitt KG. Tabletting. In: Salman AD, Hounslow M, Seville JPK. (Eds.). Handb Powder Technol Granulation Elsevier; 2006. p. 735-78.

20. Diarra H, Mazel V, Busignies V, Tchoreloff P. Investigating the effect of tablet thickness and punch curvature on density distribution using finite elements method. IntJ Pharm 2015;493:121-8.

21. Wu CY, Seville JPK. A comparative study of compaction properties of binary and bilayer tablets. Powder Technol 2009;189:285-94.

22. Podczeck F. Theoretical and experimental investigations into the delamination tendencies of bilayer tablets. Int J Pharm 2011;408:102-12.

23. Cazes R. A QbD approach to shorten tablet development time. Pharm Technol Solid Dos Drug Dev Manuf 2018;Suppl 42:16-20.

24. Akseli I, Iyer S, Lee HP, Cuitino AM. A quantitative correlation of the effect of density distributions in roller-compacted ribbons on the mechanical properties of tablets using ultrasonics and $\mathrm{x}$ ray tomography. AAPS PharmSciTech 2011;12:834-53.

25. Akseli I, Ladyzhynsky I, Katz J, He X. Development of predictive tools to assess capping tendency of tablet formulations. Powder Technol 2013;236:139-48.

26. Mazel V, Busignies V, Diarra $H$, Tchoreloff P. Lamination of pharmaceutical tablets due to air entrapment: direct visualization and influence of the compact thickness. Int J Pharm 2015;478:702-4.

27. Garr JSM, Rubinstein MH. An investigation into the capping of paracetamol at increasing speeds of compression. Int J Pharm 1991;72:117-22.

28. Van Veen B, Maarschalk KVDV, Bolhuis GK, Zuurman K, Frijlink HW. Tensile strength of tablets containing two materials with a different compaction behaviour. Int J Pharm 2000;203:71-9.

29. Heckel RW. Density-pressure relationships in powder compaction. Trans Metall Soc AIME 1961;221:671-5.

30. Jain S. Mechanical properties of powders for compaction and tableting: an overview. Pharm Sci Technol Today 1999;2:2031.

31. Roberts RJ, Rowe RC. Mechanical properties. Pharmaceut Taylor and Francis; 1995.

32. Asgharnejad M, Storey DE. Application of a compaction simulator to the design of a high-dose tablet formulation. Part I. Drug Dev Ind Pharm 1996;22:967-75.

33. Inman SJ, Briscoe BJ, Pitt KG. Topographic characterization of cellulose bilayered tablets interfaces. Chem Eng Res Dis 2007;85:1005-12.

34. Peleg M. Flowability of food powders and methods for its evaluation-a review. J Food Process Eng 1977;1:303-28. 
35. Aulton E, Taylor K. Particle science and powder technology. In: Elsevier Health Sciences (Ed.). Aulton's Pharm Des Manuf Med; 2013. p. 187-98.

36. Mullarney MP, Hancock BC, Carlson GT, Ladipo DD, Langdon BA. The powder flow and compact mechanical properties of sucrose and three high-intensity sweeteners used in chewable tablets. Int J Pharm 2003;257:227-36.

37. Lindberg NO, Palsson M, Pihl AC, Freeman R, Freeman T, Zetzener $\mathrm{H}$, et al. Flowability measurements of pharmaceutical powder mixtures with poor flow using five different techniques. Drug Dev Ind Pharm 2004;30:785-91.

38. Amidon GE, Houghton ME. The effect of moisture on the mechanical and powder flow properties of microcrystalline cellulose. Pharm Res 1995;12:923-9.

39. Li Q, Rudolph V, Weigl B, Earl A. Interparticle van der waals force in powder flowability and compactibility. Int J Pharm 2004;280:77-93.

40. Tye CM, Sun C, Amidon GE. Evaluation of the effects of tableting speed on the relationships between compaction pressure, tablet tensile strength and tablet solid fraction. J Pharm Sci 2005;94:465-72.

41. Sugisawa K, Kaneko T, Sago T, Sato T. Rapid quantitative analysis of magnesium stearate in pharmaceutical powders and solid dosage forms by atomic absorption: method development and application in product manufacturing. J Pharm Biomed Anal 2009;49:858-61.

42. Yamamura T, Ohta T, Taira T, Ogawa Y, Sakai Y, Moribe K, et al. Effects of automated external lubrication on tablet properties and the stability of eprazinone hydrochloride. Int J Pharm 2009;370:1-7.

43. Blicharski T, Swiader K, Serefko A, Kulczycka Mamona S, Kolodziejczyk M, Szopa A. Challenges in technology of bilayer and multi-layer tablets: a mini-review. Curr Issues Pharm Med Sci 2019;32:229-35.

44. Akseli I, Abebe A, Sprockel O, Cuitino AM. Mechanistic characterization of bilayer tablet formulations. Powder Technol 2013;3236:30-6.

45. Lacombe R. Adhesion measurement methods: theory and practice. CRC Press; 2005.

46. Cremer K, Asmussen B. Novel controlled-release tablet with erodible layers. Proc Int Controlled Release Bioact Mater 1995;22:732-3.

47. Dietrich P, Cremer K, Bauer Brandl A, Schubert R. Complex layer tablets-aspects of a new tabletting technology. Pharm Sci 1998;1:318.

48. Dietrich P, Cremer K, Bauer Brandl A, Schubert R. Adhesion strength in two-layer tablets. Pharm Res 1997;14:429.

49. Fell JT, Newton JM. Determination of tablet strength by the diametral-compression test. J Pharm Sci 1970;59:688-91.

50. Pitt KG, Newton JM, Richardson R, Stanley P. The material tensile strength of convex-faced aspirin tablets. J Pharm Pharmacol 1989;41:289-92.

51. Li SP, Karth MG, Feld KM, Di Paolo LC, Pendharkar CM, Williams RO. Evaluation of bilayer tablet machines-a case study. Drug Dev Ind Pharm 1995;21:571-90.

52. Yang L, Venkatesh G, Fassihi R. Compaction simulator study of a novel triple-layer tablet matrix for industrial tableting. Int J Pharm 1997;152:45-52.

53. Karehill PG, Glazer M, Nyström C. Studies on direct compression of tablets. XXIII. The importance of surface roughness for the compatibility of some directly compressible materials with different bonding and volume reduction properties. Int J Pharm 1990;64:35-43.

54. Takeuchi H, Yasuji T, Yamamoto H, Kawashima Y. Spray-dried lactose composite particles containing an ion complex of alginate-chitosan for designing a dry-coated tablet having a time-controlled releasing function. Pharm Res 2000;17:94-9.

55. Muzzio FJ, Lerapetritou M, Portillo P, Llusa M, Levin M, Morris $\mathrm{KR}$, et al. A forward-looking approach to process scaleup for solid dose manufacturing. In pharmaceutical dosage forms tablets. CRC Press 2008;3:135-68.

56. Podczeck F. Methods for the practical determination of the mechanical strength of tablets-from empiricism to science. Int J Pharm 2012;436:214-32.
57. Klinzing G, Zavaliangos A. Understanding the effect of environmental history on bilayer tablet interfacial shear strength. Pharm Res 2013;30:1300-10.

58. Park CR, Munday DL. Development and evaluation of a biphasic buccal adhesive tablet for nicotine replacement therapy. Int J Pharm 2002;237:215-26.

59. Singh SD. Bilayer tablet technology: an overview. J Appl Pharm Sci 2011;1:43-7.

60. Conley R, Gupta SK, Sathyan G. Clinical spectrum of the osmoticcontrolled release oral delivery system (OROS), an advanced oral delivery form. Curr Med Res Opin 2006;22:1879-92.

61. Lende LKLK, Banerjee SK, Gadhave MV, Gaikwad DD, Gaykar AJ. Review on: bilayer floating tablet. Asian J Pharm Res Dev 2013;1:31-9.

62. Ijaz H, Qureshi J, Danish Z, Zaman M, Abdel Daim M, Bashir I. Design, and evaluation of bilayer matrix tablet of metoprolol tartrate and lisinopril maleate. Adv Polym Technol 2017;36:152-9.

63. Kamila MM, Mondal N, Ghosh LK, Gupta BK. Multiunit floating drug delivery system of rosiglitazone maleate: development, characterization, statistical optimization of drug release and in vivo evaluation. AAPS PharmSciTech 2009;10:887.

64. Rekhi GS. Advances in solid dose oral drug delivery. ON Drug Delivery: Oral Drug Delivery and Advanced Excipients; 2010. p. 14-8.

65. Rayakwar N, Dangi YS. Development and characterization of controlled release bilayered tablets of citicoline sodium. J Drug Dev Ther 2019;9:125-31.

66. $\mathrm{Hu} \mathrm{L}, \mathrm{Hu} \mathrm{Q}$, Kong D. Formulation and in vitro evaluation of aspirin and isosorbide 5-mono-nitrate sustained bilayer tablets. Int J Pharm Life Sci 2014;5:799.

67. Melocchi A, Parietti F, Loreti G, Maroni A, Gazzaniga A, Zema L. 3D printing by fused deposition modeling (FDM) of a swellable/erodible capsular device for oral pulsatile release of drugs. J Drug Delivery Sci Tech 2015;30:360-7.

68. Gopinath $\mathrm{C}$, Bindu VH, Nischala M. An overview on bilayered tablet technology. J Global Trends Pharm Sci 2013;4:1077-85.

69. Nagaraju R, Kaza R. Formulation and evaluation of bilayer sustained-release tablets of salbutamol and theophylline. Int J Pharm Sci Nanotech 2009;2:638-46.

70. Kumar V, Prasad G, Ganesh B, Swathi C, Rashmi A, Reddy A. Development, and evaluation of guaifenesin bilayer tablet. Int J Pharm Sci Nanotech 2010;3:1122-8.

71. Yeole PG, Khan S, Patel VF. Floating drug delivery systems: need and development. Indian J Pharm Sci 2005;67:265.

72. Busignies V, Mazel V, Diarra $H$, Tchoreloff $P$. Role of the elasticity of pharmaceutical materials on the interfacial mechanical strength of bilayer tablets. Int J Pharm 2013;457:260-7.

73. Akhtar M, Jamshaid M, Zaman M, Mirza AZ. Bilayer tablets: a developing novel drug delivery system. J Drug Delivery Sci Tech 2020:102079.

74. Louie Helm J, Berner B. Formulation of an erodible, gastric retentive oral dosage form using in vitro disintegration test data. United States Patent 10,281,284; 2003.

75. Demiri V, Stranzinger S, Rinner P, Piller M, Sacher S, Lingitz J, et al. Gluing pills technology: a novel route to multilayer tablet manufacturing. Int J Pharm 2018;548:672-81.

76. Paudel A, Raijada D, Rantanen J. Raman spectroscopy in pharmaceutical product design. Adv Drug Delivery Rev 2015;89:3-20.

77. Zhang Y, McGeorge G. Quantitative analysis of pharmaceutical bilayer tablets using transmission raman spectroscopy. J Pharm Innov 2015;10:269-80.

78. Seo KS, Han HK. Multilayer-coated tablet of clopidogrel and rosuvastatin: preparation and in vitro/in vivo characterization. Pharmaceutics 2019;11:313.

79. Agiba AM, Eldin AB. Insights into formulation technologies and novel strategies for the design of orally disintegrating dosage forms: a comprehensive industrial review. Int J Pharm Pharm Sci 2019;11:8-20.

80. Agiba AM, Abdel-Hamid S, Nasr M, Geneidi AS. Geriatric oriented high dose nutraceutical ODTs: formulation and physicomechanical characterization. Curr Drug Delivery 2018;15:267-77. 
81. Khan KA. The concept of dissolution efficiency. J Pharm Pharmacol 1975;27:48-9.

82. Agiba AM. Liquisolid technology: a state-of-the-art review on the current state, challenges, new and emerging technologies for next generation. Curr Drug Delivery 2020;17:736-54.

83. Agiba AM, Hakeem WA, Zayed AG. Modulatory effect of polymer type and concentration on drug release from sustained release matrix tablets of ranolazine: a comparative release kinetic study. Asian J Pharm Clin Res 2020;13:132-40.

84. Podczeck F. Comparison of in vitro dissolution profiles by calculating mean dissolution time (MDT) or mean residence time (MRT). Int J Pharm 1993;97:93-100.

85. Wagner JG. Interpretation of percent dissolved-time plots derived from in vitro testing of conventional tablets and capsules. J Pharm Sci 1969;58:1253-7.

86. Higuchi T. Rate of the release of medicaments from ointment bases containing drugs in suspension. J Pharm Sci 1961;50:874-5.
87. Hixon AW, Crowell JH. Dependence of reaction velocity upon surface and agitation. Ind Eng Chem 1931;23:923-31.

88. Korsmeyers RW, Gumy R, Doelker EM, Buri P, Peppas NA Mechanism of solute release from porous hydrophilic polymers. Int J Pharm 1983;15:25-35.

89. Karudumpala S, Gnanaprakash K, Venkatesh B, Sankar P, Balaji G, Vidya Sagar N. Formulation, and evaluation of gastroretentive floating bilayer tablets of nifedipine. AJADD 2013;20131:341-57.

90. Center for Drug Evaluation and Research (U. S.). Orange book: approved

91. of bilayer technology: a novel approach. J Pharm Pharm Sci 2015;2:148-61.

92. Cunha Filho M, Gelfuso GM, Gratieri T. Subdivision of modifiedrelease tablets: state-of-the-art and future perspectives. Ther Delivery 2020;11:5.

93. Rantanen J, Khinast J. The future of pharmaceutical manufacturing sciences. J Pharm Sci 2015;104:3612-38. 